\title{
Sociedad de acciones simplificadas, oportunidad de organización y trascendencia para las pequeñas empresas familiares.
}

\author{
Sergio Félix Enríquez ${ }^{1}$ \\ Fernando Calles Montijo ${ }^{2}$ \\ Ana Elsa Ortiz Noriega ${ }^{3}$
}

\section{Resumen}

En el país como en el mundo entero, las pequeñas y medianas empresas representan más del $95 \%$ de las entidades económicas que dedicadas a la actividad productiva, en gran mayoría representada por empresas familiares, enfrentan múltiples problemáticas objeto de estudio a través del tiempo, que han dado pie a posibles soluciones enfocadas al proceso de administración y trabajo dentro de la formalidad.

Tanto el sector gubernamental como las asociaciones empresariales, han buscado siempre como apoyar a este tipo de unidades económicas a permanecer y ser competitivas en el mundo empresarial.

La reforma financiera de 2014 , relacionada con las modificaciones a la Ley General de Sociedades Mercantiles en 2016, da origen a la nueva Sociedad de Acciones Simplificada, la cual viene a impactar directamente como una oportunidad a las pequeñas y medianas empresas familiares, pretenden ayudar a fortalecer su economía, ampliar sus oportunidades en la actividad económica y fortaleciéndolas, sirviendo de impulso para trascender y ser más productivas.

Palabras Claves: Empresas familiares, Sociedad de Acciones Simplificadas, Mipyme's.

\begin{abstract}
In the country and the world, small and medium-sized enterprises account for over $95 \%$ of economic entities engaged in productive activity, most represented by family businesses face multiple problems under study over time, which they have led to possible solutions focused on process management and work within formality.
\end{abstract}

Both the government sector and business associations, have always sought how to support this kind of economic units to remain and be competitive in the business world.

Financial reform of 2014, regarding changes to the General Law of Commercial Companies in 2016, giving rise to the new Society of simplified joint stock, which comes to impact directly as an opportunity for small and medium-sized family businesses, seek help strengthen its economy and expand their opportunities in economic activity, strengthening and supporting them to transcend and be more productive.

Keywords: Family Business, Society Simplified Shares MSMEs.

${ }^{1}$ Contador Publico. Doctor en Administración Educativa. Profesor de Tiempo completo del Departamento de Contabilidad. Coordinador del programa de Contaduría Pública. Universidad de Sonora.sfelix@guaymas.com.mx

${ }^{2}$ Contador Publico. Doctor en Desarrollo Regional y Tecnológico. Profesor de Tiempo Completo del Departamento de Contabilidad. Coordinador del programa de la Maestría en Impuestos. Universidad de Sonora. fcalles@eca.uson.mx

${ }^{3}$ Contador Publico, Doctora en Administración Educativa. Profesora de Tiempo Completo del Departamento de Contabilidad de la Universidad de Sonora .aeortiz@guaymas.com.mx 


\section{Reportes de investigación}

\section{Introducción.}

En la economía nacional como a nivel mundial, la pequeña y mediana empresa son el motor que la mueve y factor importante para su crecimiento. En México de acuerdo con el INEGI del total de las unidades económicas que dan empleo a los mexicanos, según INEGI 2014, el 99\%, corresponden a las micro, pequeña y mediana empresa que básicamente son del núcleo familiar, generando el $52 \%$ del producto interno bruto y el $77 \%$ de los empleos en el país. Lo mismo sucede en Estados Unidos donde el 95\% de los negocios son de tipo familiar. Como se puede observar esto comprueba la gran importancia que las empresas familiares representan para el desarrollo de cualquier país, ya que son el tipo de empresas predominantes en el mundo.

Muchas de las grandes compañías del mundo son o tuvieron su origen en una empresa familiar. Estas nacen por lo regular de una propuesta que sus fundadores refuerzan con el deseo de construir un patrimonio que asegure el bienestar y futuro de sus descendientes, que también puede ser la vía para solucionar el problema de desempleo de sus iniciadores. Incluso, las grandes organizaciones buscan el modelo de una gran familia para crear la armonía necesaria que demanda un ambiente de trabajo amable con el individuo. Una empresa familiar sana y organizada abre los caminos hacia el éxito de una organización competitiva. De acuerdo con la firma de prestadores de servicios profesionales KPGM en su artículo "Empresas Familiares: El desafío de crecer, madurar y permanecer, en México más del 90\% de las empresas que cotizan en la Bolsa Mexicana de Valores tienen una clara representación familiar en el capital y en el control de la organización" lo cual refleja la importancia que representa para el sector el conducir adecuadamente desde sus inicios una entidad familiar y no terminar en el intento. El problema es que cuando nacen sin planeación alguna la desaparición es muy alta, más del $85 \%$ en la primera generación, de acuerdo con datos económicos publicada por INEGI, y más del $75 \%$ de los nuevos negocios no rebasan más de 3 años de existencia.
Uno de los factores que inciden en el éxito o fracaso de este tipo de empresas además de la calidad en su administración, es la forma de organización sea como persona física o persona moral, y en el país es importante considerar a la organización como un sociedad administrada profesionalmente.

Visualizar una empresa desde una familia o miembro de ésta ha sido común a lo largo de la vida y no es sino hasta finales de los años sesenta cuando empezaron a aparecer en Inglaterra los primeros artículos especializados acerca del estudio de la Empresa Familiar. Durante la siguiente década se comenzaron a realizar las primeras investigaciones y modelos de su estructura y comportamiento organizacional. Pero el verdadero auge llegó hace poco más de 20 años. La empresa de familia "se descubrió" en la década de los ochenta. Actualmente continúa en ascenso el interés mundial por conocer y manejar adecuadamente el conjunto familia-empresapropiedad, en especial aquellos que dan un enfoque sistémico basados en los estudios del comportamiento familiar. Por lo anterior, cita en su obra "Anzola, Sérvulo. 2002. Administración de pequeñas y medianas empresas" no se puede entender la sociedad y la economía de la llamada cultura occidental, sin referirse a la figura de la empresa familiar, donde el $40 \%$ de empleos es generado por este tipo de empresas en occidente.

El proceso de recopilación de la historia de la empresa familiar facilita a todos los miembros de la familia empresaria recordar su historia común: Recordar de dónde vienen y así, transmitir el legado a las siguientes generaciones.

Hay conciencia del enorme poder motivador que posee la historia. Quizá el ejemplo más ilustrativo son los equipos deportivos profesionales cuyos entrenadores antes de los partidos importantes a menudo recurren a contar y transmitir las grandes historias sobre los hombres valientes que lucharon "contra el viento y marea" y lograron victorias épicas. Una empresa familiar no tiene que recurrir a los libros de historia para motivar sus miembros y las generaciones futuras. Basta con recordar su propia historia.

\section{6 / Trascender, Contabilidad y Gestión}




\section{Problemática de las empresas familiares}

El estudio de las empresas familiares ayuda a explicar las principales ventajas y desventajas que impactan en este tipo de organizaciones, porque es una constante a nivel nacional la falta de conocimiento en los empresarios. Es importante fomentar un conocimiento sobre este tipo de empresas, su organización, las formas de administrarse, y que en esta ocasión se enfoca a la formas de organizarse para llevar a cabo el negocio desde el punto de vista legal, es decir la forma de constituir la empresa, lo que mejorara la competitividad entre las empresas familiares y así poderlas llevar al éxito con estrategias basadas en la información.

Peggy Lambing y Charles Kuehl (1998), en su libro "Empresarios Pequeños y Medianos" mencionan: Una de las preguntas más elementales difíciles de responder es: “¿Qué es un empresario?” Peter Drucker, autoridad en la teoría de la administración, ha dicho que aunque el término empresario se ha utilizado por más de 200 años, "ha habido una confusión total sobre la definición". La palabra empresario se deriva de los vocablos franceses que significan "entre" y "tomar"; por lo que un empresario es aquel que toma una posición entre un proveedor y un comprador - el que "toma" el riesgo, literalmente, de llegar a tener éxito.

Peter Drucker definió al empresario como una persona que saca los recursos económicos de un área y los lleva a otra de mayor productividad y rendimiento.

Tal vez una de las mejores definiciones de ser empresario o emprendedor, como se ha dado a llamar a últimas fechas - es la que expreso Jeffrey A. Timmons, profesor de enfoque empresarial y autor de The Entrepreneurial Mind.

Ser empresario significa tomar acciones humanas, creativas para construir algo de valor a partir de prácticamente nada. En la búsqueda insistente de la oportunidad independientemente de los recursos disponibles o de la carencia de estos, requiere una visión y la pasión y el compromiso para guiar a otros en la persecución de dicha visión. También requiere la disposición de tomar riesgos calculados.

Oscar Sánchez, María Sotelo y Martha Mota (2008), mencionan que los empresarios son las personas que toman decisiones que ayudaran a configurar el sistema económico de libre empresa del nuevo milenio, descubriendo necesidades del mercado y lanzando nuevas empresas para satisfacer tales necesidades. Buena parte del impulso para el cambio, innovación y progreso en nuestra economía procederá de los empresarios, aquellos seres llenos de energía que asumen riesgos y disparan el crecimiento económico.

El mundo de hoy está lleno de oportunidades para los empresarios. Una carrera empresarial puede ofrecer una vida excitante que contribuya al bienestar de la sociedad así como a recompensas financieras considerables.

Aunque algunos especialistas limitan el término empresario para los fundadores de empresas de negocios, en una definición más amplia, se incluyen a todos los propietariosadministradores, y abarca a los miembros de segunda generación de empresas de propiedad familiar y administradores propietarios que compran empresas existentes de manos de fundadores. Sin embargo nuestra definición excluye a los administradores de sueldo, a corporaciones mayores y también a aquellos que parecen empresarios por su gusto por la innovación o disposición para asumir riesgos.

Los empresarios en diversas industrias sirven a la economía ofreciendo empleos y produciendo bienes y servicios para los clientes en este país y alrededor del mundo. Aunque las corporaciones gigantes atraen más atención pública y logran más encabezados en los medios noticiosos, los pequeños negocios y las iniciativas empresariales constituyen una parte menos visible de la economía, que es igualmente importante para el bienestar económico y social del mundo. (Sánchez, Sotelo y Mota; 2008)

La formación de un empresario es un proceso en el cual intervienen un sinnúmero de variables sociales, culturales, psicológicas y económicas que contribuyen, con un conjunto de conocimientos específicos, a desarrollar una serie de competencias que buscan lograr que este empresario en formación tenga altas probabilidades de convertirse en un empresario exitoso, capaz de generar riqueza y desarrollo social a lo largo de su vida. 


\section{Reportes de investigación}

De acuerdo con KPGM, los factores que inciden en la desaparición de una micro, pequeña o mediana empresa son entre otros la mala planeación, falta de capacitación, el poco capital y conocimientos en el área de negocios emprendida y los temas relacionados con la administración, una organización poco clara para la toma de decisiones sobre compras, los empleados y el manejo de recursos financieros, la falta de una buena gestión, políticas y lineamientos sobre los propietarios y los familiares de éstos que creen que el negocio debe servirle a ellos y no el de agregar valor a la organización.

Se considera que un negocio de tipo familiar puede ser diferente a otros ya que además de la problemática normal que afrontan las organizaciones, éstas tienen que enfrentar otras como el desafío que significa alinear los intereses de la familia, la propiedad y los objetivos del negocio, por lo que se debe planear y organizar desde la estructura y forma de organizar la empresa hasta planear las decisiones con respecto a la cadena de mandos, promociones y sucesiones dentro de la institución, situación que pocos lo hacen.

Es importante una verdadera capacitación y conocimiento del medio con respecto a las mipymes y sobre todo empresas familiares, lo cual mejoraría las expectativas de negocios y su permanencia en el mercado. Los gobiernos en el país han apoyado a este tipo de negocios con recursos, fondos y programas de capacitación, así como las instituciones de educación con el ofrecimientos de programas académicos enfocados a la profesionalización de conducción y creación de negocios, así mismo las organizaciones empresariales preocupadas por la problemática impulsan al interior de las mismas, programas de apoyo a estas pequeñas empresas.

Ejemplos de programas de apoyo a este tipo de empresas son: "crédito joven", dirigido a emprendedores novatos con una edad entre 18 a 30 años de edad con montos que van desde 50 mil hasta 2.5 millones de pesos con tasas prefe- renciales y a mediano plazo. Otro programa es "Crédito para crecer juntos" dirigido a personas físicas inscritos en el régimen de incorporación fiscal, que consiste en créditos desde 20 mil hasta 300 mil pesos, siempre y cuando la empresa ya tenga más de 2 años de operar.

Otro programa es "Alianza Pyme" con montos un poco más elevados, que van desde los 100 mil hasta los 12 millones de pesos, con el fin de respaldar a empresas a consolidarse en el mercado. Los dos primeros programas apoyados al $100 \%$ por parte de Nacional Financiera y en el tercero por parte de esta misma institución y Banco Nacional de Comercio Exterior. (García, 2016)

Para que un negocio funcione adecuadamente es importante que sus propietarios se involucren y conozcan sobre temas jurídicos, financieros y de administración ya que en el país pareciera que a los empresarios poco les importa estos temas, y solo acuden a los especialistas hasta que tienen un problema por resolver.

De acuerdo con Expansión en su portal empresarial, las empresas familiares cometen varios errores desde su formación, que contribuyen a no subsistir más allá de la segunda generación. Entre estos errores los 8 más comunes son: Finanzas poco claras iniciando por asignar por parte de sus fundadores puestos innecesarios a sus descendientes como sueldos muy elevados para que logren mantener un buen ritmo de vida y no por sus méritos en la labor.

Otro error que se comete es sangrar el negocio reflejándose en que algunos clientes gozan de descuentos preferenciales, otorgamiento de créditos lo que significa no alinear políticas de ventas con mercadotecnia.

Ego Fundador es otro error lo que se interpreta como que el crecimiento y transcendencia de la empresa suele limitarse a la capacidad del fundador o líder. 
El paternalismo como se trata generalmente de pequeñas empresas, la cercanía del líder o fundador con sus empleados los convierte como un padre adoptivo que les resuelve problemas.

La dependencia excesiva hace que cuando falta el fundador del grupo familiar, muchas empresas sufren un revés que las puede hacer desaparecer.

Nula institucionalización, si el fundador de una empresa familiar tiene la visión y que la empresa trascienda tendrá que optar por la institucionalización y dejar la organización en manos de expertos o profesionales.

El decidir quién asciende o quien sucede al fundador es factor importante para no desaparecer el no decidirlo puede influir para no subsistir por parte de este tipo de empresas (www.expansion.mx. 2013).

Estos errores clásicos deben ser analizados por los administradores de empresas familiares para lograr el crecimiento de las mismas, sobre todo cuando no se decide el ejecutar las acciones de manera profesional desde su misma constitución.

Ejemplo de lo anterior, es cuando se funda una empresa como sociedad, los dueños no saben que deben acudir a diversas instancias y cumplir con una serie de requisitos como el que un notario público protocolice un acta constitutiva que contiene las disposiciones básicas de funcionamiento y objetivos de la persona moral y su administración, así como la responsabilidad de sus integrantes. En la realidad muchos negocios se inician no con el conocimiento, sino por la obligación de contemplar un documento que les de sustento, y esta condición se refleja cuando se manifiestan empresas sin gobierno, sin control o falta de estrategias bien definidas.

El origen de las sociedades de acciones simplificadas, puede venir a resolver parte de la problemática que enfrentan las pequeñas organizaciones, en cuanto a su estructura organizativa y de operación mercantil, facilitando la tramitología que enfrentan las organizaciones formalmente estruc- radas en base a la Ley General de Sociedades Mercantiles.

\section{Formas jurídicas de formar una empresa.}

En el país existen diversas formas de organizar jurídicamente una empresa, una vez analizado el plan de negocios y contar con los recursos necesarios para invertir, en una organización debidamente planeada debe optarse por la forma en que ha de funcionar, existiendo varias formas para hacerlo: sea como persona física o autónoma o como persona moral, esta implica el elegir como una sociedad mercantil, sociedad civil, asociación civil o cooperativa o fundaciones. La forma dependerá de que actividad y fines tiene la empresa, que generalmente es de tipo mercantil y con fines de lucro.

En México el establecer un negocio, requiere de infinidad de trámites y registros los cuales implican tiempo y costo, lo cual para facilitar y promover la inversión, las autoridades han pretendido simplificar dicha tramitología y recortando los tiempos de ejecución para incrementar la actividad económica en todos los sectores, y a través del tiempo se han modificado y creado nuevas leyes para lograr tal fin.

\section{Sociedades de Acciones Simplificada (SAS)}

En el marco de lo anterior como antecedente la modificación de la Ley General de Sociedades Mercantiles y como parte de la reforma financiera ejercida por la actual administración federal llevada a cabo en el año de 2014, que entre otros aspectos considera la inclusión financiera, cuya finalidad es acercar y hacer más común los aspectos financieros en las personas físicas lo cual trajo por consecuencia la creación de un nuevo tipo de sociedad, misma que ayuda a las pequeñas empresas a formalizar e institucionalizar como negocio. (Félix Todd, 2016) 


\section{Reportes de investigación}

Las sociedades de acciones simplificas no son nuevas en Latinoamérica, en Colombia ya existen como una herramienta de planeación sucesoria entre otros objetivos, que desde hace 40 años existe en este país, y como tal desde 2008 siendo esta una buena referencia para darle origen a este tipo de sociedades en nuestro país adicionalmente a lo considerado anteriormente.(Ginebra,2005)

La actualización de la legislación financiera es consecuencia de la participación activa de México como país en la actividad económica mundial a través de la Organización para la Cooperación y Desarrollo Económico (OCDE). "La reforma a la Ley General de Sociedades Mercantiles se basa en el proyecto de ley modelo sobre entidades mercantiles simplificadas elaborada por la comisión de naciones unidas para el derecho mercantil internacional" (Todd, 2016, P13).

La reforma se enfoca a las micro y pequeñas empresas para ser consideradas como parte de una sociedad simplificada y que estas sociedades fueran constituidas por una o más personas físicas o morales.

El hecho de constituir una sociedad con una sola persona, se enfoca a la exigencia actual en las relaciones comerciales donde se exige mayor seguridad y confianza cuando dicha relación se da con una persona moral debidamente formada de acuerdo con la ley que con una persona física.

El espíritu de la modificación a la ley al crear las SAS, es la protección del patrimonio personal de las personas físicas que practiquen una actividad mercantil y de igual manera el patrimonio familiar, por lo que se puede considerar que esta es una buena opción para las empresas familiares. Según Higuera Arias e Higuera Ornelas en la Revista Contaduría Pública de 2016, los principales beneficiados con este tipo de sociedades a los pequeños emprendedores de negocios sin que encuentren obstáculos en el camino para una pronta constitución y que no tenga el carácter de oneroso.
Lo anterior se puede constatar en lo establecido por el capítulo XIV de la LGSM, donde se prevé una forma ágil y sencilla de formarla ante la Secretaría de Economía a través de los medios digitales y de manera gratuita sin ningún otro intermediario o fedatario público.

\section{Constitución de la Sociedad Mercantil.}

En el mes de marzo de 2016, se publica el decreto en el que se reforma la LGSM, manifestándose una nueva figura de sociedad mercantil, misma que entrará en vigor a partir del 15 de septiembre del mismo año.

En el artículo de dicha ley, se reconoce los siguientes tipos de sociedades:

I. Sociedad en Nombre Colectivo.

II. Sociedad en Comandita Simple

III. Sociedad de Responsabilidad Limitada.

IV. Sociedad Anónima.

V. Sociedad en Comandita por acciones.

VI. Sociedad Cooperativa.

VII. Sociedad por acciones simplificada.

Siendo esta última fracción la que se adiciona para dar origen a este nuevo régimen societario. Así mismo para poder cumplir con el funcionamiento de esta nueva figura mercantil, se requirió de modificar el artículo $2^{\text {do }}$ de la LGSM que establece la obligación de inscribirse ante la Secretaría de Economía para que surta efectos ante terceros y se modificó el artículo $5^{\text {to }}$ refiriéndose al mecanismo de constitución que se establece en el capítulo XIV de la misma ley, así mismo el artículo 20 exenta a las SAS de separar de sus utilidades netas anuales para formar el fondo de reserva.

Los artículos antes mencionados y el nuevo capítulo XIV, que habla de esta nueva sociedad, conforman el fundamento legal para esta oportunidad que puede representar para las empresas familiares de institucionalizar y fortalecer su actuación, dándole mayores garantías legales de subsistencia y desarrollo.

\section{0 / Trascender, Contabilidad y Gestión}


De acuerdo con la ley una sociedad de acciones simplificada se define como "aquella que se constituye con una o más personas físicas que solamente están obligadas al pago de sus aportaciones representada por acciones. En ningún caso las personas físicas podrán ser simultáneamente accionistas de otro tipo de sociedad mercantil a que se refieren las fracciones I a VII, del artículo $1^{\circ}$ de esta ley, si su participación en dichas sociedades mercantiles les permite tener el control de la sociedad o de su administración, en términos del artículo 2, fracción III de la Ley del Mercado de Valores" (LGSM, art.260).

Este tipo de sociedades se pueden considerar como unipersonales ya que como se deduce del artículo anteriormente citado, se puede conformar con una sola persona, situación que prácticamente sucede en la actualidad con las sociedades anónimas pequeñas o familiares donde quien lleva el control financiero y administrativo es el socio mayoritario sin intervención en las decisiones del resto de la sociedad, y lo cual es apegado a ley, pero con todo el riesgo que implica el formar parte de la misma.

A diferencia de otros tipos de sociedades mercantiles, la SAS, la ley contempla un proceso de constitución simplificada y sin costo alguno para la misma, tal y como se plasma en el artículo 262 de la LGSM ya que solo debe cumplir con lo siguiente:

1. Que haya uno o más accionistas

2. Que los accionistas externen su consentimiento para constituir este tipo de sociedad bajo los estatutos sociales que la Secretaría de Economía ponga a disposición mediante el sistema electrónico de constitución.

3. Que alguno de los accionistas cuente con autorización para el uso de denominación emitida por la Secretaría de Economía y

4. Que todos los accionistas cuenten con certificado de firma electrónica avanzada vigente reconocido en las reglas generales que emita la Secretaría de Economía.

\section{Principales características de las Sociedades por Acciones Simplificada}

En base a lo establecido en el capítulo XIV de la LGSM, se distinguen las siguientes características que identifican a la sociedad lo cual representan algunas ventajas con respecto al resto de las sociedades mercantiles que reconoce la misma ley y facilitan y apoyan el funcionamiento de las pequeñas empresas familiares ayudándoles a permanecer en el mercado:

Las características y condiciones anteriores fueron previstas por el legislador con fin de facilitar la conformación de negocios de manera informal, de combatir la informalidad y fomentar y apoyar a las pequeñas empresas, incluidas las familiares. 


\section{Reportes de investigación}

\section{Principales características de las Sociedades por Acciones Simplificada}

\begin{tabular}{|c|c|}
\hline Socios & $\begin{array}{l}\text { Una o más personas físicas, razón por la cual se le considera que puede ser uni- } \\
\text { personal. No se admite personas morales como socios. Deberán contar con su } \\
\text { firma electrónica avanzada. }\end{array}$ \\
\hline Responsabilidad & $\begin{array}{l}\text { La responsabilidad de sus socios se limita solo al pago de sus aportaciones. En } \\
\text { caso de comisión de conductas sancionadas como delitos, responderán de ma- } \\
\text { nera subsidiaria, solidaria e ilimitadamente. }\end{array}$ \\
\hline Formalidad & $\begin{array}{l}\text { Se constituye a través del sistema electrónico de constitución (SE), de la Secreta- } \\
\text { ría de Economía, no requiere de acudir ante notario público al menos que los so- } \\
\text { cios lo requieran. }\end{array}$ \\
\hline Estatutos & $\begin{array}{l}\text { Los estatutos pueden ser seleccionados por los socios de los ofrecidos por la } \\
\text { Secretaría de Economía a través del SEC. }\end{array}$ \\
\hline Reservas & $\begin{array}{l}\text { A diferencia del resto de las sociedades no requiere separar utilidades para crear } \\
\text { el fondo de reserva que establece el art. } 20 \text { de LGSM. }\end{array}$ \\
\hline Documento & $\begin{array}{l}\text { La sociedad no requiere de escritura constitutiva, basta con el contrato social } \\
\text { electrónico y boleta de inscripción }\end{array}$ \\
\hline $\begin{array}{l}\text { Inscripción al registro } \\
\text { publico }\end{array}$ & $\begin{array}{l}\text { El SEC, de la Secretaría de Economía, genera una folio mercantil que emite la } \\
\text { boleta de inscripción ante el Registro Público de la Propiedad y el Comercio de } \\
\text { manera automática. }\end{array}$ \\
\hline Órgano Supremo & $\begin{array}{l}\text { La asamblea general de accionistas es el órgano supremo y está integrado por } \\
\text { todos los accionistas. Los acuerdos se llevan en el libro de registro de resolucio- } \\
\text { nes. }\end{array}$ \\
\hline Órgano representativo & $\begin{array}{l}\text { La representación de la sociedad estará a cargo de un administrador. Si la socie- } \\
\text { dad es de una sola persona, ésta será el administrador. }\end{array}$ \\
\hline Participación & $\begin{array}{l}\text { Los accionistas tienen voz y voto y las acciones son del mismo valor con los mis- } \\
\text { mos derechos y obligaciones. }\end{array}$ \\
\hline Capital & No hay capital social mínimo. \\
\hline Ingresos & $\begin{array}{l}\text { No deberán rebasar los } 5,000,000.00 \text { de pesos anuales, actualizable anualmente } \\
\text { de acuerdo al factor de actualización publicado por la Secretaría de Economía. }\end{array}$ \\
\hline Registros & $\begin{array}{l}\text { EI SEC, permitiría registrar automáticamente a la sociedad ante el Registro Fede- } \\
\text { ral de Contribuyentes y ante el Instituto Mexicano del Seguro Social, así como en } \\
\text { coordinación con estados y municipios se puede hacer los registros locales en } \\
\text { línea mediante la misma plataforma. }\end{array}$ \\
\hline Información & $\begin{array}{l}\text { El administrador de la sociedad es el responsable de publicar en el sistema elec- } \\
\text { trónico, el informe anual de la situación financiera. Si no se hace en dos años } \\
\text { consecutivos será causa de disolución de la sociedad. }\end{array}$ \\
\hline $\begin{array}{l}\text { Transformación de la } \\
\text { sociedad }\end{array}$ & $\begin{array}{l}\text { En cualquier otro tipo de sociedad cuando rebase el mínimo de ingresos permiti- } \\
\text { dos }\left(\$ 5^{\prime} 000,000.00\right) \text { o por decisión de los socios. }\end{array}$ \\
\hline
\end{tabular}

\section{Fuente: Elaboración propia de los autores con información de la Ley General de Sociedades}

\section{Conclusiones.}

La empresa familiar no solamente es un instrumento para producir y distribuir riqueza. Hacer negocios con la familia tiene una gran motivación, lo que busca es ser factor de fortalecimiento y seguridad familiar; y es aquí en donde la empresa debe y quiere ser factor de unión de la familia. A la vez, la familia busca facilitar la buena marcha de la empresa.

Es un hecho que a nivel mundial y en el país las pequeñas y medianas empresas son el motor de la economía ya que representas mas del $95 \%$ de las organizaciones formalmen- te constituidas y que las empresas familiares presentan grandes problemas tanto de competitividad, organización y administración que hacen que las lleven a desaparecer y no trascender más allá de la segunda generación siendo la mínima cantidad las que logran subsistir y crecer. Muchas de las grandes empresas existentes iniciaron como empresas familiares y de acuerdo a la visión y preparación de sus fundadores han logrado crecer de esta manera. 
En un afán de apoyar a este sector económico, han existido una gran cantidad de apoyos, programas y fondos para lograr hacer subsistir a las empresas.

Un gran problema de las micros, pequeñas y medianas empresas además de su calidad en la organización y lo que conlleva al interior de las familias empresarias, es la falta de organización y/constitución, contratos, proyectos, programas de proveeduría de los grandes consorcios y del sector gobierno, no puede acceder este tipo de empresas por la forma en que están organizadas, es decir al querer participar en este tipo de actos se les requiere que estén constituidas como sociedades.

La propuesta y concreción de la modificación a la Ley General de Sociedades Mercantiles y crear la Sociedad de Acciones Simplificadas, uno de sus principales objetivos es apoyar y fomentar la formalidad y en apoyo de las pequeñas empresas familiares para darles competitividad y facilidad de conformarse como tales, disminuyendo costos y tramitología que les ayude a funcionar como todo una sociedad.

Este aspecto legal sin duda fomenta la participación de las pequeñas empresas familiares en la economía y auxiliadas por una adecuada capacitación de sus administradores ayudará a trascender en el mercado de los negocios.

\section{Bibliografía}

Anzola, Sérvulo. 2002. Administración de pequeñas y medianas empresas. $2^{a}$. Edición. Ed. MacGraw-Hill. México.

www.kpmg.com.mx Empresas Familiares: El desafío de crecer, madurar y permanecer 2014, recuperado el 28 agosto de 2016

www.inegi.org. $\mathrm{mx} /$

Lambing Peggy y Kuehl Charles Administración de pequeñas y medianas empresas. 6ª edición, 2010.

Sánchez L Oscar R., Sotelo S. María Elena, Mota P. Martha J. Introducción a la Contaduría, primera edición, 2008García Ramírez José Luis. Revista Abaco del Colegio de Contadores Públicos del Estado de Sonora, 2016.

Todd Piñero Félix, Revista Contaduría Pública, IMCP, 2016.

Ginebra, J. (2005). Las empresas familiares: su dirección y su continuidad. Panorama Editorial.

http://dof.gob.mx/nota_detalle.php?

codigo $=5429707 \&$ fecha $=14 / 03 / 2016 \&$ print=trueLey General de Sociedades Mercantiles.

www.expansion.mx/emprendedores/.../8-errores-de-lasempresas-familiares. 2013, recuperado 5 de agosto de 2016 